\title{
Lipid Rafts Serve as a Signaling Platform for Nicotinic Acetylcholine Receptor Clustering
}

\author{
Dan Zhu, Wen C. Xiong, and Lin Mei \\ Program of Developmental Neurobiology, Institute of Molecular Medicine and Genetics and Department of Neurology, Medical College of Georgia, Augusta, \\ Georgia 30912
}

Agrin, a motoneuron-derived factor, and the muscle-specific receptor tyrosine kinase (MuSK) are essential for the acetylcholine receptor (AChR) clustering at the postjunctional membrane. However, the underlying signaling mechanisms remain poorly defined. We show that agrin stimulates a dynamic translocation of the AChR into lipid rafts-cholesterol and sphingolipid-rich microdomains in the plasma membrane. This follows MuSK partition into lipid rafts and requires its activation. Disruption of lipid rafts inhibits MuSK activation and downstream signaling and AChR clustering in response to agrin. Rapsyn, an intracellular protein necessary for AChR clustering, is located constitutively in lipid rafts, but its interaction with the AChR is inhibited when lipid rafts are perturbed. These results reveal that lipid rafts may regulate AChR clustering by facilitating the agrin/MuSK signaling and the interaction between the receptor and rapsyn, both necessary for AChR clustering and maintenance. These results provide insight into mechanisms of AChR cluster formation.

Key words: lipid rafts; neuromuscular junction; nicotinic acetylcholine receptors; agrin; MuSK; rapsyn

\section{Introduction}

The vertebrate neuromuscular junction (NMJ) is a synapse formed between motoneurons and skeletal muscle fibers. Because of easy accessibility and peripheral location, the NMJ has been a most extensively studied synapse (Sanes and Lichtman, 2001). A signature of the NMJ is the accumulation of nicotinic acetylcholine receptors (AChRs) in the postsynaptic membrane. Three molecules are absolutely essential for NMJ formation: agrin, an extracellular glycoprotein (McMahan, 1990); musclespecific receptor tyrosine kinase (MuSK) (Glass et al., 1996); and rapsyn, an intracellular protein that interacts with the AChR (Frail et al., 1988). Agrin activates MuSK and subsequently induces activities of several intracellular enzymes, including Abl (Finn et al., 2003), geranylgeranyltransferase I (Luo et al., 2003), Rho-family GTPases (Weston et al., 2000), and p21-activated kinase 1 (PAK1) (Luo et al., 2002). Rapsyn is a cytoplasmic peripheral membrane protein that is precisely colocalized with AChRs in vivo (Bloch and Froehner, 1987; Gautam et al., 1995). In rapsyn mutant myotubes, agrin activates MuSK but does not induce phosphorylation or clustering of AChRs, indicating that rapsyn transduces the action of agrin-activated MuSK (Gautam et al., 1995; Apel et al., 1997). Although much progress has been made toward understanding the mechanism for NMJ formation, exactly how the agrin/MuSK signaling leads to AChR clusters remains unclear.

\footnotetext{
Received July 7, 2005; revised March 27, 2006; accepted March 28, 2006.

This work was supported in part by grants from the National Institutes of Health (L.M., W.C.X.), the Muscular Dystrophy Association (L.M.), and the Philip Morris External Research Program (L.M.).

Correspondence should be addressed to Lin Mei, Program of Developmental Neurobiology, Institute of Molecular Medicine and Genetics, Medical College of Georgia, CB2803, 1120 15th Street, Augusta, GA 30912. E-mail: Imei@mcg.edu.

DOI:10.1523/JNEUROSCI.2807-05.2006

Copyright $\odot 2006$ Society for Neuroscience $\quad$ 0270-6474/06/264841-11\$15.00/0
}

Plasma membranes of many cell types contain microdomains that are biochemically distinct from bulk plasma membrane, commonly referred to as lipid rafts (Simons and Ikonen, 1997; Brown and London, 1998). These domains, enriched in sphingolipids and cholesterol, are believed to be able to diffuse laterally in the plasma membrane. They may serve as floating shuttles to bring together activated receptors and transducer molecules. For example, lipid rafts are necessary for signaling pathways initiated by IgE (Baird et al., 1999), T-cell antigen receptor activation (Janes et al., 2001), and glial cell line-derived neurotrophic factor receptor activation (Tansey et al., 2001). In the nerve system, disruption of lipid rafts prevents neurons from responding properly to trophic factors, including neuregulin and BDNF (Ma et al., 2003; Suzuki et al., 2004).

In this study, we investigated the function of lipid rafts in AChR clustering. We show that the AChR and MuSK translocate into lipid rafts after agrin stimulation. Disruption of lipid rafts inhibits agrin-induced formation and maintenance of AChR clusters. We investigated the role of lipid rafts in MuSK signaling and AChR clustering. The results indicate that the dynamic translocation of MuSK is necessary for the activation of signaling pathways essential for AChR clustering. In addition, the interaction of the AChR with rapsyn, which is present in lipid rafts constitutively, requires lipid rafts. These results identified a critical role of lipid rafts in AChR clustering.

\section{Materials and Methods}

Materials. Methyl- $\beta$-cyclodextrin (MCD), gelatin, genistein, fluoresceinconjugated cholera toxin B subunit (FITC-CTX) and D-threo-1-phenyl-2decanoylamino-3-morpholino-1-propanol (PDMP) were obtained from Sigma (St. Louis, MO). Interferon-gamma was obtained from BioSource (Camarillo, CA). $\alpha$-Bungarotoxin ( $\alpha$-BTX), biotin conjugated $\alpha$-BTX, and Alexa Fluor 594-conjugated $\alpha$-BTX were obtained from Invitrogen (Eugene, OR). Cyanogen bromide-activated Sepharose beads were ob- 
tained from Amersham Biosciences (Piscataway, NJ). Primary antibodies were obtained from Santa Cruz Biotechnology (caveolin-3, s.c.-5310 and transferrin receptor, s.c.-9099; Santa Cruz, CA) and Upstate Biotechnology (mouse anti-phosphotyrosine 4G10, catalog number 05-321, and mouse anti-Rac, catalog number $05-389$; Lake Placid, NY). Anti- $\alpha$ AChR antibody (mAb210) and anti- $\beta$-AChR antibody (mAb124) were gifts from Dr. J. Lindstrom (University of Pennsylvania Medical School, Philadelphia, PA). Anti-synaptophysin antibody was obtained from Dako (A0010; High Wycombe, UK). Rabbit anti-MuSK antibody was generated using GST-fusion protein containing amino acids 517-569 of mouse MuSK (Luo et al., 2002). Rabbit anti-rapsyn antibody was generated using GST-fusion protein containing N-terminal fragment of mouse rapsyn. Soluble recombinant neural agrin was prepared from COS cells with cDNA encoding the $\mathrm{COOH}$-terminal half of agrin (Ferns et al., 1993).

Cell culture. Mouse muscle $\mathrm{C} 2 \mathrm{C} 12$ cells were maintained in a nutrientrich growth medium containing DMEM supplemented with $20 \%$ fetal bovine serum, $0.5 \%$ chicken embryo extract, $2 \mathrm{~mm}$ L-glutamine, 100 $\mathrm{U} / \mathrm{ml}$ penicillin, and $100 \mathrm{mg} / \mathrm{ml}$ streptomycin at $37^{\circ} \mathrm{C}$ in an atmosphere of $5 \% \mathrm{CO}_{2}$ and $95 \%$ humidity. To induce differentiation, myoblasts at $50-70 \%$ confluence were switched to the differentiation medium,
DMEM supplemented with $4 \%$ horse serum, and $2 \mathrm{mM}$ L-glutamine. Rapsyn-/- (clone 11-7) and control (clone 12-10) myoblasts, generously provided by Dr. Christian Fuhrer (University of Zurich, Zurich, Switzerland), cultured as described previously (Fuhrer et al., 1999). Briefly, cells were maintained in the same basic medium as $\mathrm{C} 2 \mathrm{C} 12$ cells, with an additional $4 \mathrm{U} / \mathrm{ml} \gamma$-interferon. MuSK-/- myoblasts (generously provided by Dr. David Glass, Regeneron Pharmaceuticals, Tarrytown, NY) were cultured in basic medium as $\mathrm{C} 2 \mathrm{C} 12$ cells while with 20 $\mathrm{U} / \mathrm{ml} \gamma$-interferon. These cells were grown on dishes coated with $0.2 \%$ gelatin and maintained at $33^{\circ} \mathrm{C}$ with $5 \% \mathrm{CO}_{2}$. To induce fusion, confluent cultures were cultured in $\mathrm{C} 2 \mathrm{C} 12$ fusion medium at $37^{\circ} \mathrm{C}, 5 \% \mathrm{CO}_{2}$. In all experiments, the medium was replaced every day. Transient transfection of MuSK $-/$ - cells was performed with lipofectamine 2000 according to the instructions of the manufacturer (Invitrogen, Carlsbad, CA).

Isolation of lipid rafts. Lipid rafts were prepared as described previously (Marchand et al., 2002). Briefly, C2C12 myotubes from a $60 \mathrm{~mm}$ dish either control or treated, were collected in PBS and resuspended in $2 \mathrm{ml}$ of lysis buffer containing $25 \mathrm{~mm} 2$-[ $\mathrm{N}$-morpholino] ethanesulfonic acid, pH 6.5, $150 \mathrm{~mm} \mathrm{NaCl}, 0.5 \%$ Triton X-100, $1 \mathrm{~mm}$ PMSF, $10 \mu \mathrm{g} / \mathrm{ml}$ aprotinin, $1 \mu \mathrm{g} / \mathrm{ml}$ pepstatin $\mathrm{A}$, and $1 \mu \mathrm{g} / \mathrm{ml}$ leupeptin. Cells were homogenized by passing through a 27 gauge needle three times. Homogenates
A

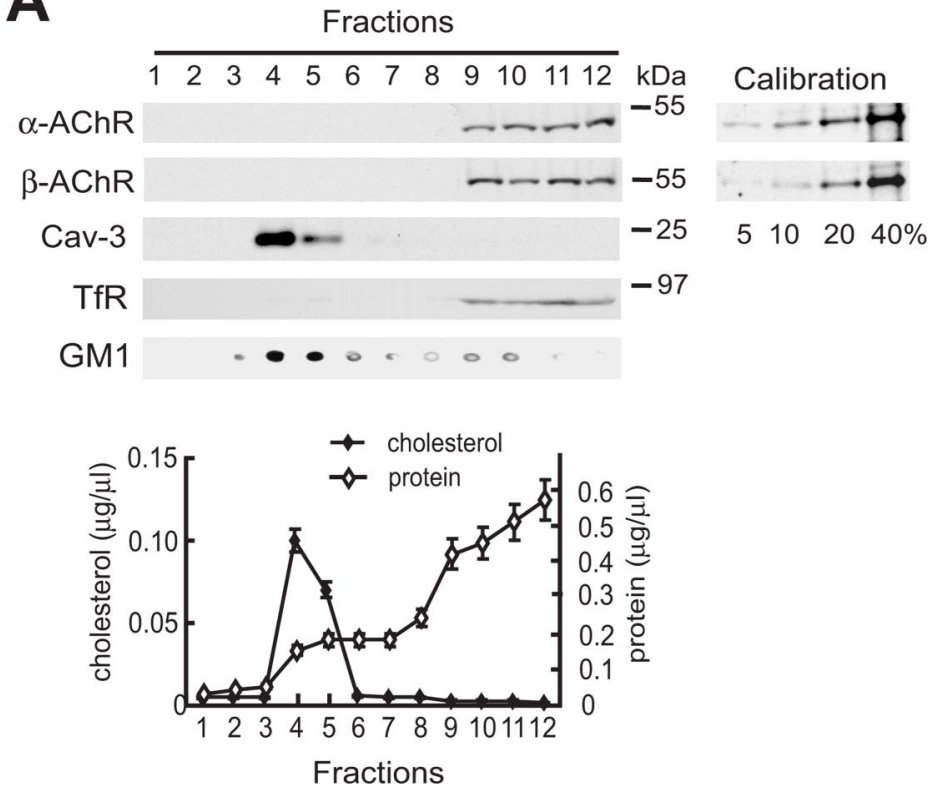

B

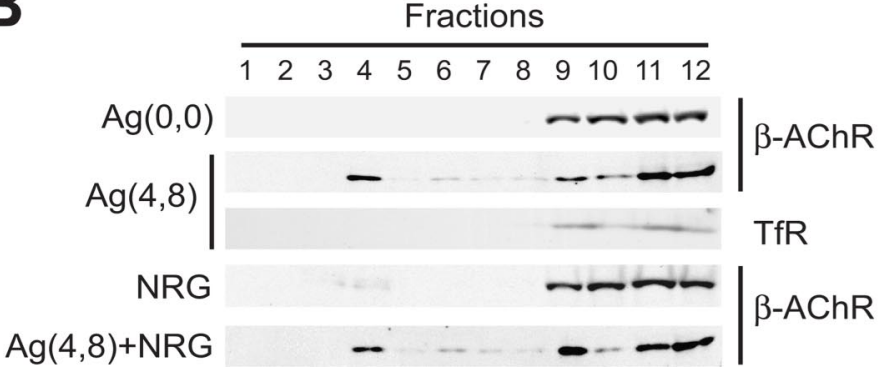

FITC-CTX

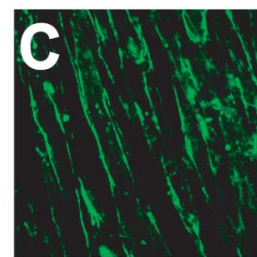

D

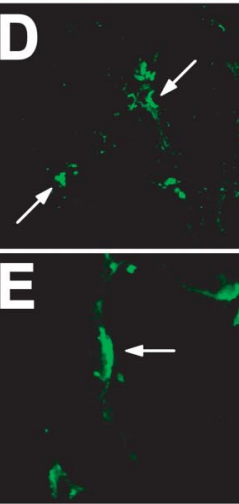

Synaptophysin

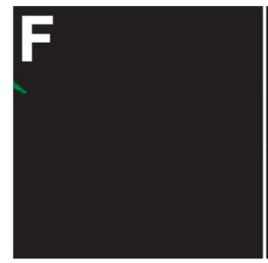

Alexa-594-BTX
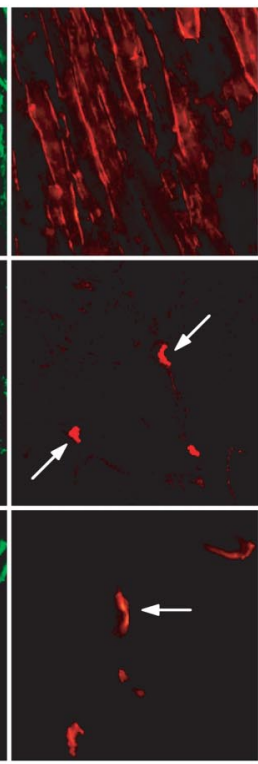

$\mathrm{AChR}$

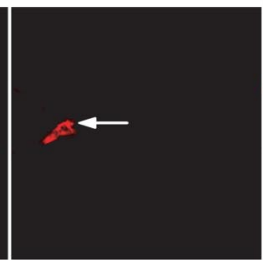

Merge
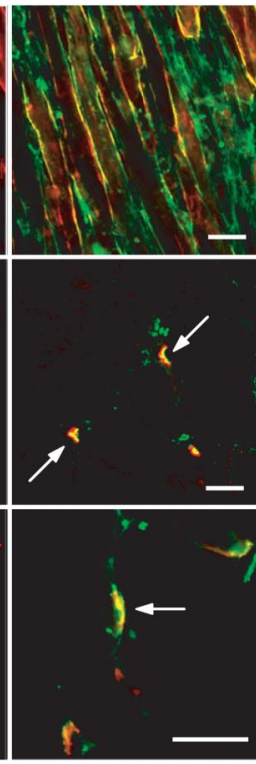

Merge

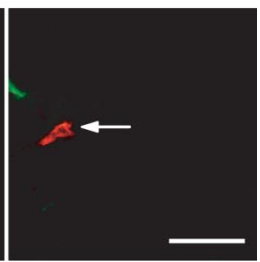

Figure 1. Dynamic translocation of the AChR into lipid rafts by agrin. $A$, Distribution of AChR in naive $C 2 C 12$ myotubes. Triton X-100-treated lysates of $C 2 C 12$ myotubes were subjected to sucrose gradient centrifugation. Twelve fractions were collected from top to bottom (1-12). Equal volumes of each of the 12 fractions were pooled together, which contain AChR in both raft and nonraft fractions and taken as $100 \%$ or input. Each fraction was subjected to Western blot analysis using indicated antibodies. GM1 was assayed by using HRP-labeled CTX. Representative blots from three independent experiments with similar results are shown. Right panels are standard curve blots showing various percentages of the input. Graphs at the bottom show protein and cholesterol content in the 12 fractions. Cav-3, Caveolin-3. B, Neural agrin-induced translocation of AChRs into lipid rafts. Myotubes were treated with $1 \mathrm{~nm}$ muscle agrin $[\mathrm{Ag}(0,0), 18 \mathrm{~h}], 1 \mathrm{~nm}$ neural agrin $[\mathrm{Ag}(4,8), 18 \mathrm{~h}]$, or $1 \mathrm{~nm}$ neural agrin for $12 \mathrm{~h}$ in the presence or absence of $2 \mathrm{~nm}$ neuregulin (NRG). Fractionation was done as in $A$. The amount of AChRs in lipid rafts (fraction 4 and 5 ) was calculated against the standard curve of different percentages of the input. ${ }^{*} p<0.01$, Student's $t$ test. $C$, AChR clusters colocalize with GM1 in $C 2$ C12 myotubes. Fully differentiated myotubes were incubated with $1 \mathrm{~nm}$ neural agrin to induce AChR clusters, and myotubes were incubated with Alexa 594-conjugated $\alpha$-BTX to stain the AChR and FITC-CTX to label GM1. D-F, Enrichment of the lipid raft marker GM1 at the NMJ. Adult rat diaphragm $(\boldsymbol{D})$ and denervated leg muscle $(\boldsymbol{E}, \boldsymbol{F})$ sections were stained for GM1 using FITC-CTX and AChR using Alexa 594-conjugated $\alpha$-BTX $(\boldsymbol{D}, \boldsymbol{E})$ or for synaptophysin $(\boldsymbol{F})$. Scale bars: $C, D, 20 \mu \mathrm{m} ; E, F, 50 \mu \mathrm{m}$. 
were mixed with $2 \mathrm{ml}$ of $80 \%$ sucrose (final concentration, $40 \%$ ), loaded at the bottom of a SW41Ti centrifuge tube (Beckman Instruments, Fullerton, CA), and overlaid with $4 \mathrm{ml}$ of $30 \%$ sucrose in the lysis buffer and $4 \mathrm{ml}$ of $5 \%$ sucrose. The sample was centrifuged at $39,000 \mathrm{rpm}$ for $16 \mathrm{~h}$ at $4^{\circ} \mathrm{C}$. Twelve fractions ( $1 \mathrm{ml}$ each) were collected from top to bottom and designated as fractions 1-12. The fractions 4 and 5 containing caveolin-3 were designated the lipid raft fractions. Detergent-free isolation of lipid rafts was performed as described previously (Song et al., 1996). To detect ganglioside GM1, $1 \mu \mathrm{l}$ of each fraction was dotted onto a nitrocellulose membrane and probed with horseradish peroxidase-coupled CTX (10 $\mathrm{ng} / \mathrm{ml}$; Sigma) as described previously (Hering et al., 2003). The concentration of cholesterol was measured using the Amplex Red cholesterol assay kit (Invitrogen) according to the instructions of the manufacturer. Protein concentration was determined using the Dc protein assay (BioRad, Hercules, CA).

Immunoprecipitation and immunoblotting. $\mathrm{C} 2 \mathrm{C} 12$ myotubes, either treated or control, were rinsed with ice-cold PBS and solubilized for 15 min on ice in modified radioimmunoprecipitation assay (RIPA) buffer supplemented with the protease inhibitors. For MuSK phosphorylation assay, lysates were centrifuged at 12,000 rpm for $10 \mathrm{~min}$, and the supernatants were immunoprecipitated at $4^{\circ} \mathrm{C}$ overnight with MuSK antibody followed by protein A beads. For phosphorylation of $\beta$-subunits or rapsyn-AChR interaction experiments, cell lysates were incubated with $\alpha$-BTX-conjugated Sepharose beads at $4^{\circ} \mathrm{C}$ overnight. After centrifugation, beads were washed four to five times with the lysis buffer. Bound proteins were eluted with SDS sample buffer and subjected to SDSPAGE. Proteins resolved on SDS-PAGE were transferred to nitrocellulose membranes (Schleicher and Schuell, Keene, NH). Nitrocellulose blots were incubated at room temperature for $1 \mathrm{~h}$ in blocking buffer (TBS with $0.1 \%$ Tween 20 and $5 \%$ milk), followed by an incubation with indicated antibodies at $4{ }^{\circ} \mathrm{C}$ overnight. For blotting with antiphosphotyrosine antibody, nitrocellulose blots were incubated with 3\% bovine serum albumin in the blocking buffer and $1 \%$ bovine serum albumin in the blotting buffer. After washing three times for $15 \mathrm{~min}$ each with TBS with $0.1 \%$ Tween 20 , the blots were incubated with horseradish peroxidase-conjugated secondary antibody (Amersham Biosciences) followed by another wash. Immunoreactive bands were visualized using enhanced chemiluminescence substrate (Pierce, Rockford, IL). All immunoblotting was repeated at least three times. In some experiments, after visualizing an immunoreactive protein, the nitrocellulose filter was incubated in a buffer containing $62.5 \mathrm{~mm}$ Tris/HCl, pH 6.7, $100 \mathrm{~mm}$ $\beta$-mercaptoethanol, and $2 \% \mathrm{SDS}$ at $50^{\circ} \mathrm{C}$ for $30 \mathrm{~min}$, washed with TBS with $0.1 \%$ Tween 20 at room temperature for $1 \mathrm{~h}$, and reblotted with different antibodies. For quantitative analysis, autoradiographic films were scanned with an Epson 1680 scanner, and the captured image was analyzed with NIH Image software.

Immunofluorescence confocal microscopy. Control and denervated $(5 \mathrm{~d}$ postdenervation) muscle sections and C2C12 myotubes were fixed in $4 \%$ paraformaldehyde (PFA), and incubated with $2 \%$ normal goat serum (Vector Laboratories, Burlingame, CA) in PBS for $1 \mathrm{~h}$ at room temperature to reduce background staining and then incubated with Alexa 594conjugated $\alpha$-BTX to label AChRs. After washing three times, the samples were incubated with FITC-CTX to label endogenous glycosphingolipids, at $10 \mu \mathrm{g} / \mathrm{ml}$ in PBS with $0.1 \%$ BSA on ice for $45 \mathrm{~min}$. Confocal microscopy was performed with a Zeiss (Thornwood, NY) confocal microscope.

AChR clustering assays. Fully differentiated C2C12 myotubes, either control or drug treated, were incubated with $1 \mathrm{~nm}$ neural agrin to induce AChR clusters. After fixation in 2\% PFA for $30 \mathrm{~min}$, cells were incubated with Alexa 594-conjugated BTX for 60 min to label AChR clusters. Myotube segments $(200 \mu \mathrm{m}$ in length) were viewed at $40 \times$ magnification with a Nikon (Tokyo, Japan) Optiphot microscope equipped with phase and epifluorescence optics, and the number of AChR aggregates was counted. AChR clusters with a shortest axis $>4 \mu \mathrm{m}$ were counted in 10 fields of each dish. Results are expressed as mean \pm SEM of at least three independent experiments.

Labeling of surface AChRs. To label surface AChRs, C2C12 myotubes were washed with cold PBS containing $1 \mathrm{~mm} \mathrm{MgCl}_{2}$ and $0.1 \mathrm{~mm} \mathrm{CaCl}_{2}$ and incubated with sulfosuccinimidyl-6-(biotin-amido)-hexanoate
(sulfo-NHS-LC-biotin) (Pierce, Rockford, IL) in the same buffer at room temperature for $30 \mathrm{~min}$. The labeling reaction was quenched by incubation with $0.1 \mathrm{~m}$ glycine for $10 \mathrm{~min}$. Cells were harvested in the modified RIPA buffer containing protease inhibitors. In some experiments, myotubes were incubated with biotin-conjugated $\alpha$-BTX at room temperature for $30 \mathrm{~min}$ to label functional surface AChRs. Lysates were incubated with streptavidin agarose beads overnight at $4^{\circ} \mathrm{C}$ to isolate biotinylated proteins, which were subjected to immunoblotting with anti-AChR subunit antibody.

In utero injection. To study the effects of lipid raft disruption on AChR clustering or $\mathrm{NMJ}$ formation in vivo, timed pregnant female mice were injected intraperitoneally with MCD or DMSO (as control) at $10 \mathrm{mg} / \mathrm{kg}$ body weight at embryonic day 14.5 (E14.5) or E18.5 once a day for $2 \mathrm{~d}$. AChR clusters were stained and quantified as described previously (Lin et al., 2005). Briefly, diaphragms were dissected and stained whole mount with Alexa 594-labeled $\alpha$-BTX and rabbit anti-synaptophysin antibody that was visualized by FITC-conjugated anti-rabbit antibody. Z-serial images were collected using a Zeiss confocal laser-scanning microscope (LSM 510 META 3.2). For AChR cluster size measurement, Z-serial images were collected with $60 \times$ oil objective.

Rac activity assay. C2C12 myotubes were treated with 5 nм neural agrin for $15 \mathrm{~min}$ and then rinsed with ice-cold PBS. Cells were then lysed
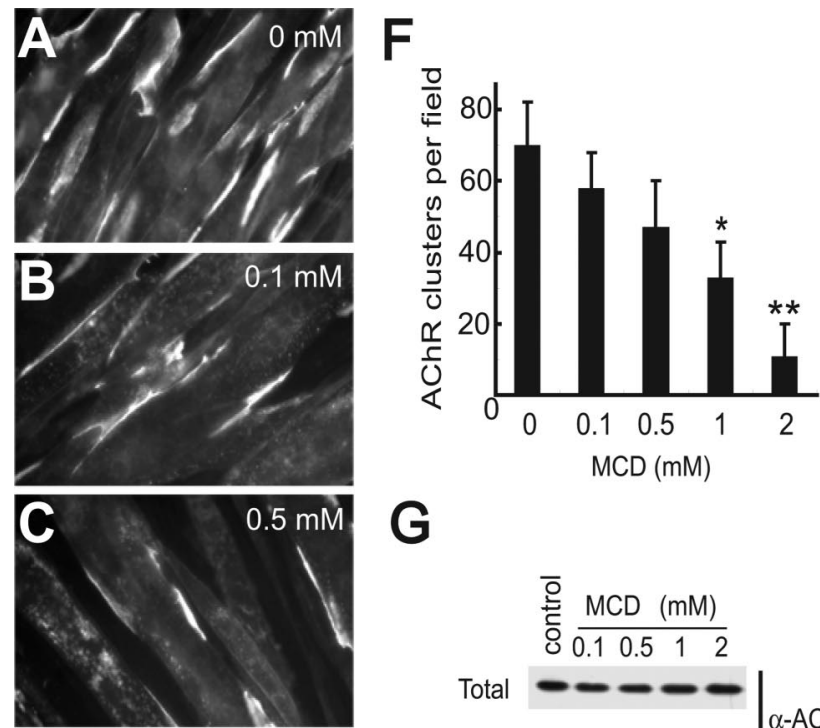

G
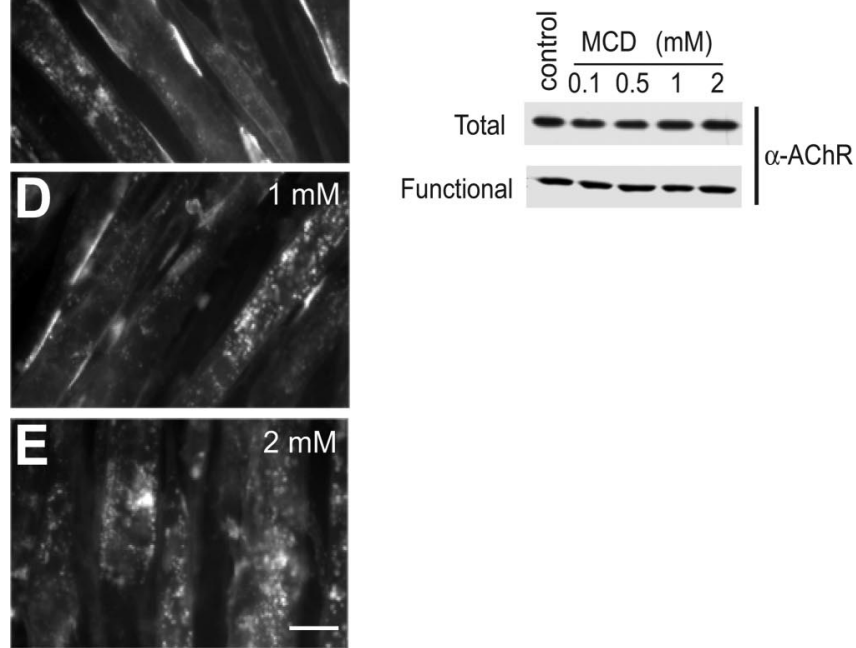

Figure 2. Disruption of lipid rafts inhibits AChR cluster formation. $\boldsymbol{A}-\boldsymbol{E}, \mathrm{C} 2 \mathrm{C} 12$ myotubes were treated with indicated concentrations of MCD along with $1 \mathrm{~nm}$ neural agrin for $8 \mathrm{~h}$ and stained with Alexa 594-conjugated $\alpha$-BTX to label AChR clusters. Scale bar, $20 \mu \mathrm{m}$. F, Quantitative analyses of AChR clusters in MCD-treated myotubes. AChR clusters, the size of which was larger than $4 \mu \mathrm{m}$, were scored. Data are shown as means $\pm \operatorname{SEM}(n=40) .{ }^{* *} p<0.001,{ }^{*} p<$ 0.01 , Student's $t$ test. $G$, Western blot analysis of surface AChR in MCD-treated myotubes. C2C12 myotubes were treated with $0-2 \mathrm{~mm} \mathrm{MCD}$ for $8 \mathrm{~h}$. Surface proteins were biotinylated, purified by streptavidin agarose beads, and probed with anti- $\alpha$-subunit antibody. For surface functional AChR labeling, myotubes were incubated with biotin- $\alpha$-BTX followed by streptavidin agarose purification. 

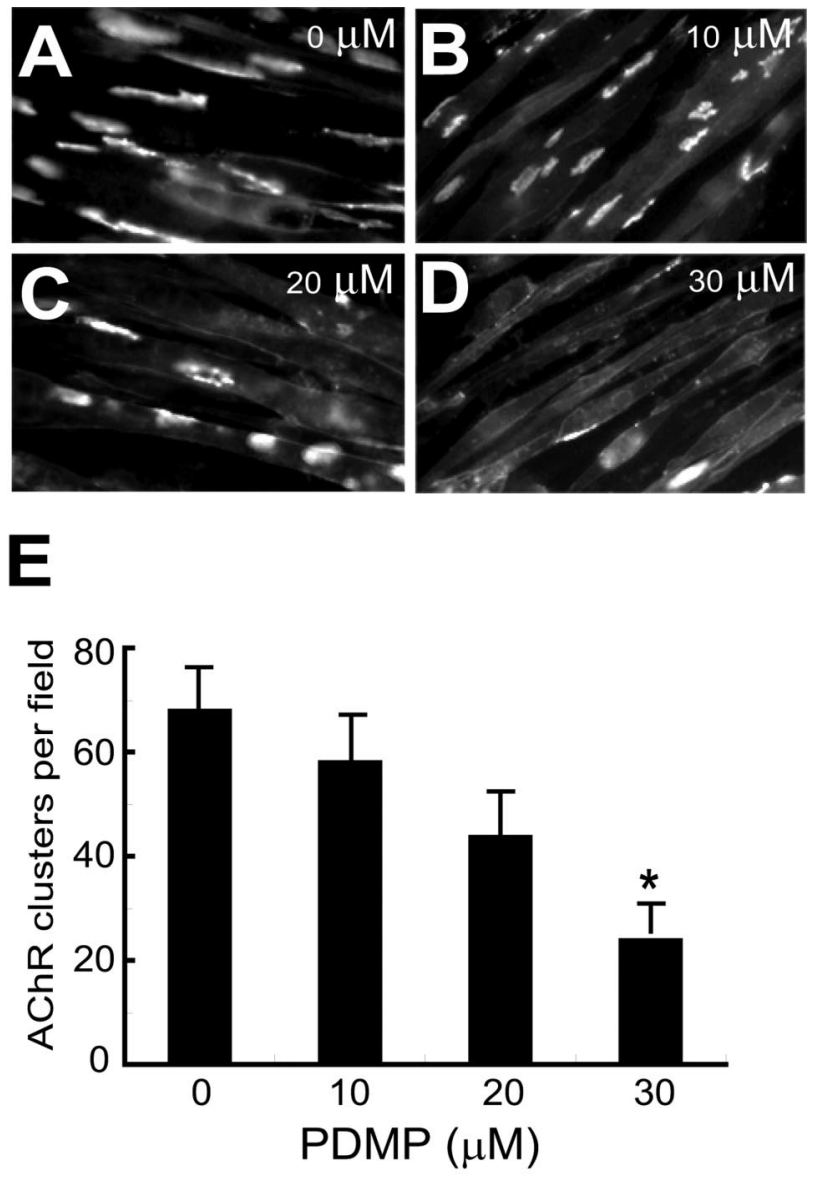

$\mathbf{F}$

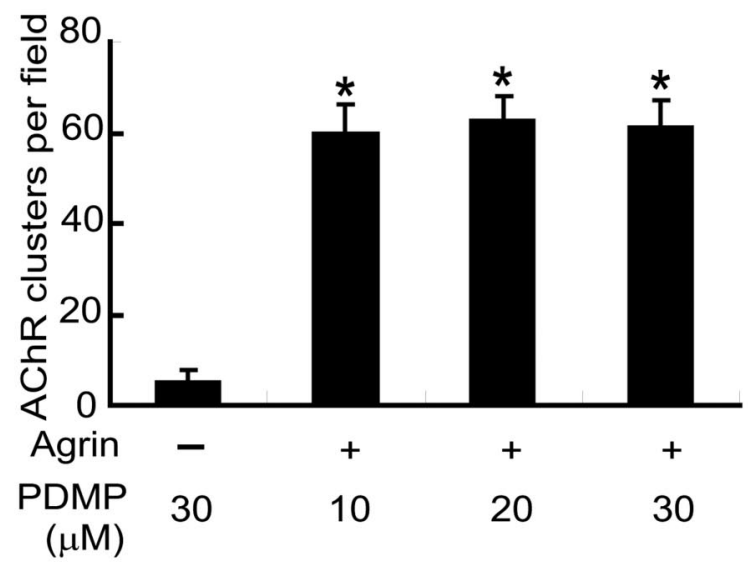

G

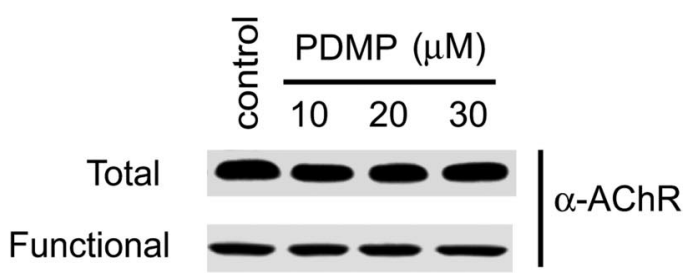

Figure 3. PDMP treatment attenuates $A C h R$ cluster formation. $A-D, C 2 C 12$ myotubes were pretreated with various concentrations of PDMP for $24 \mathrm{~h}$ before the addition of neural agrin (1 $\mathrm{nm}$, final concentration). After $8 \mathrm{~h}, \mathrm{AChR}$ clusters were visualized as in Figure 2 A. E, Quantitative analyses of AChR clusters in PDMP-treated myotubes. AChR clusters, the size of which was larger than $4 \mu \mathrm{m}$, were scored. Data are shown as means \pm SEM $(n=40) .{ }^{*} p<0.01$, Student's $t$ for 30 min on ice in modified RIPA buffer, and lysates were centrifuged for $10 \mathrm{~min}$ at $21,000 \times g$ at $4^{\circ} \mathrm{C}$. The supernatants were incubated with GST-PBD (Cdc42/Rac-binding domain of PAK fused to GST) fusion protein bound to glutathione-coupled Sepharose beads for $30 \mathrm{~min}$ at $4^{\circ} \mathrm{C}$. The beads were then washed three times in an excess of lysis buffer, eluted in SDS buffer, and then analyzed by Western blotting with mouse monoclonal antibody against Rac.

\section{Results}

Recruitment of AChRs into lipid rafts by agrin stimulation

To investigate whether the AChR associates with lipid rafts, C2C12 myotubes were solubilized in $0.5 \%$ Triton $\mathrm{X}-100$ at $4^{\circ} \mathrm{C}$ and fractionated on a floatation gradient. After centrifugation, 12 fractions were collected from the top to bottom, and each fraction was subjected to SDS-PAGE followed by immunoblotting for lipid raft markers and anti-AChR antibodies. Caveolin is a marker of lipid rafts (Evans et al., 2003; Ma et al., 2003), and its muscle isoform-caveolin-3 was present in fractions 4 and 5 (Fig. $1 A$ ). Moreover, GM1, a ganglioside component of lipid rafts, and cholesterol were also enriched in fractions 4 and 5 (Fig. $1 A$ ). These two fractions accounted for $\sim 12 \%$ of total proteins, in line with previous reports (Hering et al., 2003). These results indicate that fractions 4 and 5 are those enriched in lipid rafts and therefore designated "lipid raft" fractions. In support of this notion is the observation that the transferrin receptor (TfR), which is known not to be associated with lipid rafts, was localized in the high-density bottom fractions (Fig. $1 A$ ). AChRs, detected by antibodies against either $\alpha$ or $\beta$ subunits, were barely detectable in the top low-density fractions of the discontinuous gradient (Fig. $1 A$ ). However, they were present in the soluble, high-density bottom fractions (fractions 9-12). These results suggest that in naive $\mathrm{C} 2 \mathrm{C} 12$ myotubes, the majority of AChRs is associated with nonraft fractions.

To determine whether the localization of AChRs is regulated, C2C12 myotubes were stimulated with $1 \mathrm{~nm}$ neural agrin for $18 \mathrm{~h}$. Under this condition, the number of AChR clusters increased 10-fold (Wallace, 1988; Ferns et al., 1993; Luo et al., 2002). Agrin-treated myotubes were lysed, and resulting lysates were subjected to discontinuous density centrifugation. As shown in Figure $1 B$, AChRs were readily detectable in lipid raft fractions after agrin stimulation. The amount of AChRs in lipid rafts was increased from $3.8 \pm 0.7 \%$ in naive cells to $24.6 \pm 6.4 \%$ in agrinstimulated $(18 \mathrm{~h}$ ) cells (means $\pm \mathrm{SEM} ; n=5 ; p<0.01)$. The effect of neural agrin was specific, because muscle agrin appeared to have little effect on the distribution of AChRs. Moreover, the $\mathrm{TfR}$, which was associated with nonrafts in naive cells, remained in the nonraft fractions even after neural agrin treatment (Fig. $1 B)$. Neuregulin stimulation of muscle cells was shown to attenuate AChR clustering by agrin (Trinidad and Cohen, 2004) and recruits ErbB kinases into lipid rafts (Ma et al., 2003). We studied the effect of neuregulin on agrin-induced AChR relocation into lipid rafts. $\mathrm{C} 2 \mathrm{C} 12$ myotubes were treated with $2 \mathrm{~nm}$ neuregulin alone or in combination with $1 \mathrm{~nm}$ agrin. As shown in Figure $1 B$, neuregulin alone was unable to recruit AChRs to lipid rafts and had no consistent effect on agrin-induced AChR translocation.

\section{$\leftarrow$}

test. $\boldsymbol{F}$, C2C12 myotubes were treated with PDMP at indicated concentrations for $24 \mathrm{~h}$, washed, and incubated in the PDMP-free medium for another $24 \mathrm{~h}$. Myotubes were stimulated with $1 \mathrm{~nm}$ neural agrin for $8 \mathrm{~h}$, and $A C h R$ clusters were assayed. $G$, Western blot analysis of surface AChR in PDMP-treated myotubes. C2C12 myotubes were treated with 0-30 $\mu \mathrm{m}$ PDMP for $24 \mathrm{~h}$. Surface proteins were biotinylated, purified by streptavidin agarose beads, and probed with anti- $\alpha$ subunit antibody. For surface functional AChR labeling, myotubes were incubated with biotinBTX followed by streptavidin agarose purification. 

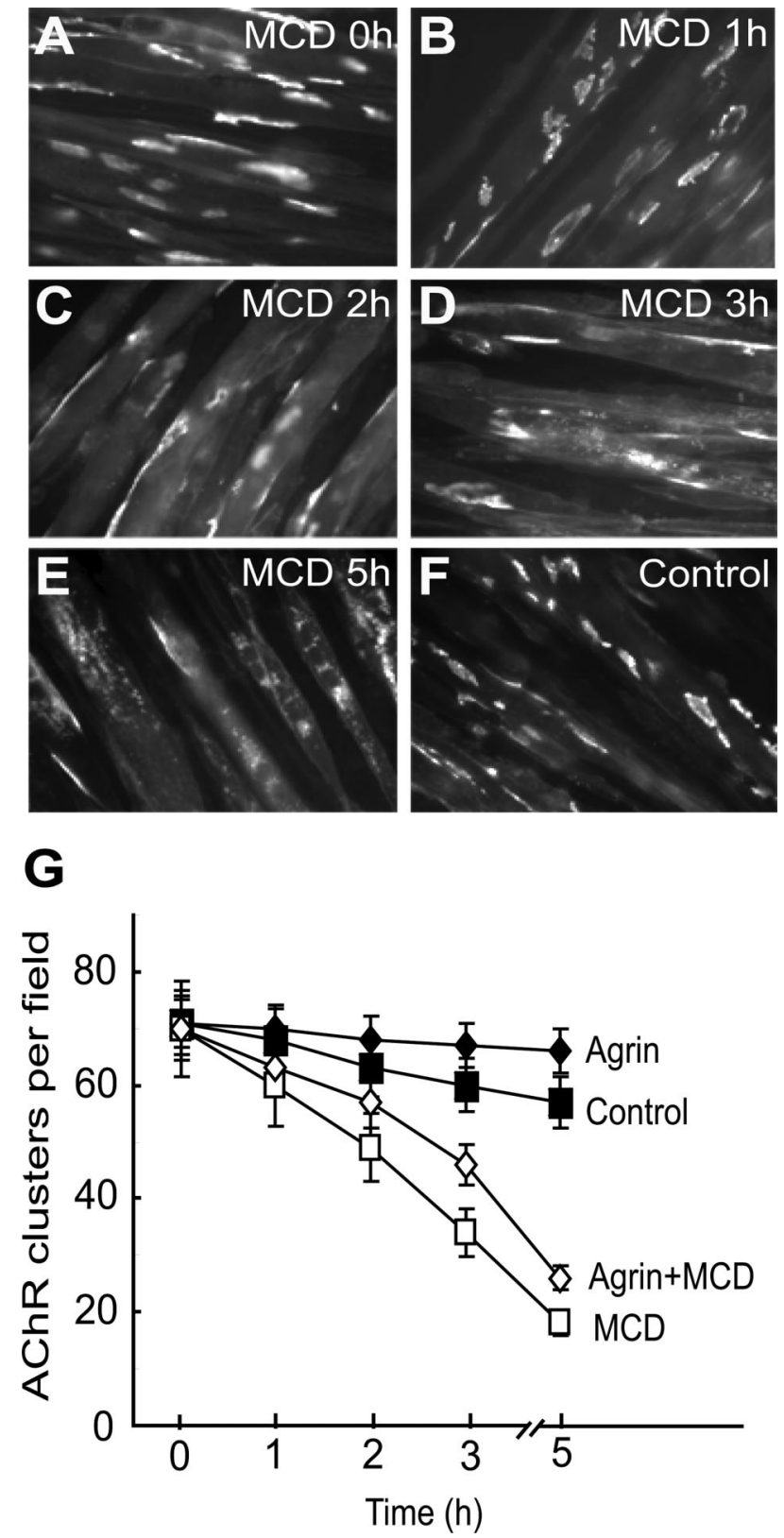

Figure 4. Decreased stability of AChR clusters in myotubes treated with $M C D . A-F, C 2 C 12$ myotubes were incubated with $1 \mathrm{~nm}$ neural agrin for $18 \mathrm{~h}$ to induce AChR clusters. Cells were washed and incubated with or without agrin in the presence or absence of $2 \mathrm{mM} M C D$ for indicated times. G, Quantitative analysis of data shown in $\boldsymbol{A}-\boldsymbol{F}$. AChR clusters, the size of which was larger than $4 \mu \mathrm{m}$, were scored. Data are shown as means $\pm \operatorname{SEM}(n=40)$.

These results indicated that agrin induces the translocation of AChRs into lipid rafts and that this effect is neural agrin specific.

To determine whether AChR clusters are colocalized with lipid rafts in muscle cells, C2C12 myotubes were stimulated with $1 \mathrm{~nm}$ agrin for $18 \mathrm{~h}$, fixed, and stained with FITC-CTX. This toxin binds to the ganglioside GM1, a component of lipid rafts (Schon and Freire, 1989), and has been used extensively as a lipid raft marker in a variety of cells and tissues (Harder et al., 1998; Bruses et al., 2001). Myotubes were costained with Alexa 594-conjugated $\alpha$-BTX to label the AChR. As shown in Figure 1C, CTX colocated with AChR clusters, suggesting that lipid rafts are associated with clustered AChR in cells. Approximately half of the GM1 clusters did not contain AChR, whereas $\sim 75 \%$ of AChR clusters colocal-

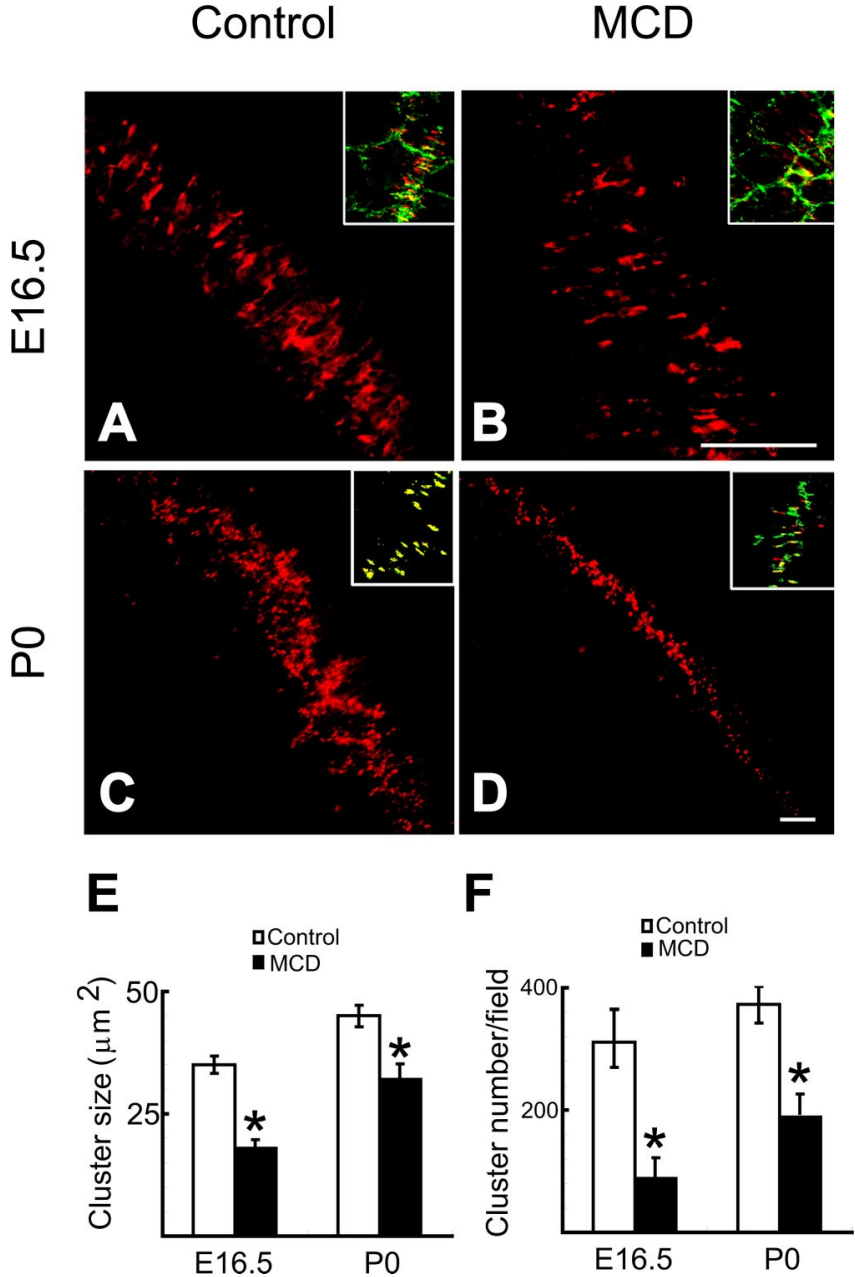

Figure 5. Lipid rafts are required for both AChR formation and maintenance in vivo. Diaphragm muscles were collected from E16.5 embryos of pregnant females injected daily with DMSO as a control $(\boldsymbol{A})$ or MCD $(\boldsymbol{B})$ and from P0 newborn pups of pregnant mice injected with DMSO ( $C$ and MCD (D) starting atE18.5. Whole-mount diaphragm muscles were double stained with Alexa 594-conjugated $\alpha$-BTX and anti-synaptophysin antibodies. In contrast to numerous and larger clusters in controls, few and smaller AChRs were present in mice treated with MCD. Inset, Synaptophysin-rich nerve terminals (green) were apposed by AChR clusters (red) (yellow color indicates colocalization) in controls, whereas in MCD-treated mice, nerve terminals were not well apposed by AChR clusters. Quantitative analysis of average area $\left(\mu \mathrm{m}^{2}\right)$ of individual AChR clusters $(\boldsymbol{E})$ and numbers of AChR clusters/field $(\boldsymbol{F})$ was measured as described in Materials and Methods. Data are shown as means \pm SEM $(n=35) .{ }^{*} p<0.01$, compared with controls; Student's $t$ test. Scale bars, $100 \mu \mathrm{m}$.

ized with GM1. Subsequently, we investigated whether lipid rafts are enriched at the NMJ by staining rat diaphragm sections with CTX and $\alpha$-BTX. GM1 showed a pattern of labeling strikingly similar to that of the BTX staining (Fig. 1D). Merging the two images indicated that GM1 is localized at the NMJ. To eliminate possible contamination by presynaptic nerve terminals, muscles were denervated, which causes rapid degeneration of nerve terminals. Before the development of pathological conditions, expression of postsynaptic proteins is normal or elevated to compensate the loss of presynaptic input (Tanowitz and Mei, 1996; Tanowitz et al., 1999). As shown in Figure 1, E and F, GM1 as well as AChR, but not synaptophysin, a presynaptic marker, remained in denervated muscles. These suggest that AChRs are associated with lipid rafts in the postjunctional membrane. These observations reveal that clustered AChRs were localized in lipid rafts in cultured muscle cells and at the NMJ, suggesting a role of the microdomains in AChR clustering. 


\section{Disruption of lipid rafts inhibits AChR} cluster formation and stability

If lipid rafts are important for AChR clusters, their disruption should inhibit AChR cluster formation. To test this hypothesis, C2C12 myotubes were treated with MCD, a water-soluble cyclic oligomer that sequesters cholesterol within its hydrophobic core, thereby depleting cholesterol from the plasma membrane and dispersing lipid rafts (Simons and Toomre, 2001; Tansey et al., 2001; Ma et al., 2003). Before investigating the effect of MCD on AChR clustering, we determined its effect on myotube viability. Quantitative analysis using trypan blue exclusion indicated that the percentage of dead myotubes after MCD treatment $(0.1-2 \mathrm{~mm} ; 8 \mathrm{~h})$ was the same as control $(\sim 0.6 \%)$. Furthermore, there was no difference in morphology between control and MCD-treated myotubes (data not shown). Thus, MCD did not affect the viability of cultured C2C12 cells under these conditions. In the presence of MCD, however, agrin-induced AChR aggregates were impaired in $\mathrm{C} 2 \mathrm{C} 12$ myotubes (Fig. 2A-E). The effect does not appear to be nonspecific, because it is concentration dependent (Fig. $2 F$ ). To ensure that the decrease in AChR clusters was caused by disruption of lipid rafts, we studied the effect of PDMP, a chemical that disrupts lipid rafts by a different mechanism (Nagafuku et al., 2003). PDMP decreases sphingolipid levels in the membrane by inhibiting glycosphingolipid biosynthesis (Inokuchi et al., 1987). PDMP treatment inhibited AChR cluster formation in a dose-dependent manner (Fig. $3 A-E$ ), in support of the view that lipid rafts are necessary for AChR clustering. The inhibitory effect of PDMP was reversible when treated myotubes were cultured in PDMP-free medium (Fig. $3 F$ ). To exclude the possibility that the reduction in AChR clusters was not caused by a decrease in surface $\mathrm{AChR}$, myotubes treated with MCD, PDMP, or vehicle were incubated with sulfo-NHS-LC-biotin to label surface proteins. Biotinylated proteins were purified with streptavidin beads and probed for the $\alpha$-subunits. The amounts of surface AChRs were similar in control cells and in cells treated with MCD or PDMP at concentrations that attenuate AChR clustering (Figs. 2G, 3G). Cholesterol has been shown to affect eletrophysiological properties of the AChR in reconstituted lipids (Barrantes, 2004). We assayed whether MCD and PDMP may affect the binding activity of the AChR to $\alpha$-BTX. Live control or treated $\mathrm{C} 2 \mathrm{C} 12$ myotubes were incubated with biotinyl-

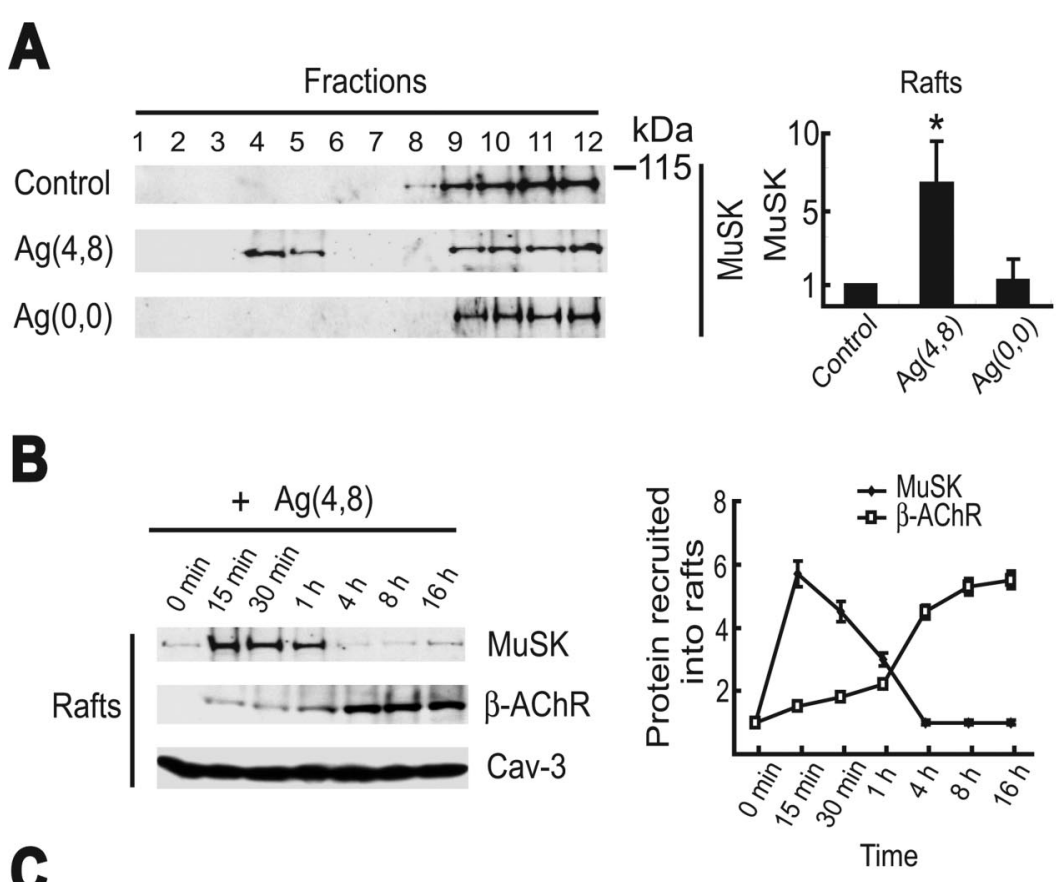

C

Fractions

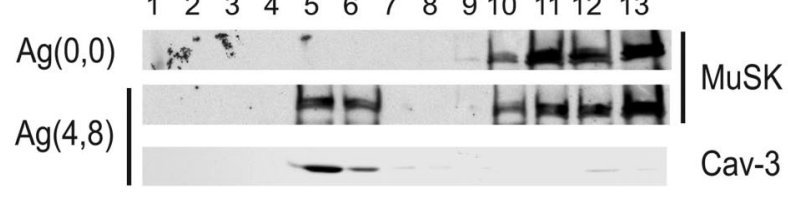

D

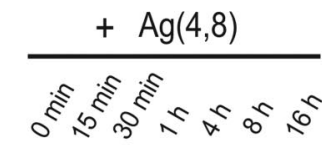

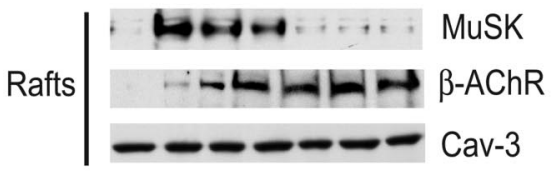

$\mathbf{E}$
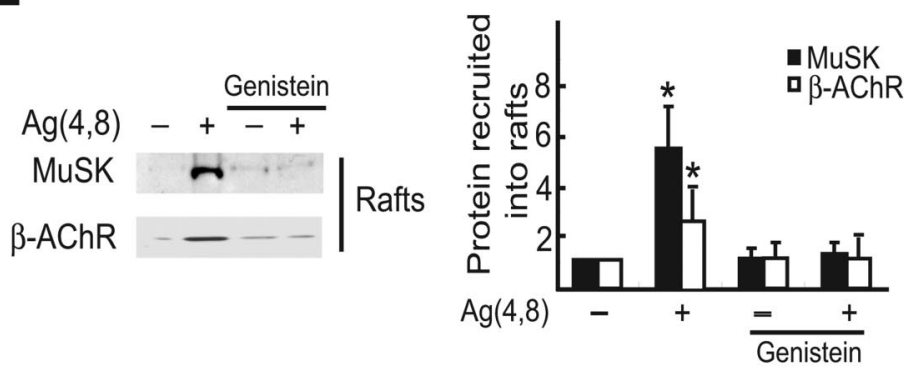

$\mathbf{F}$

Fractions

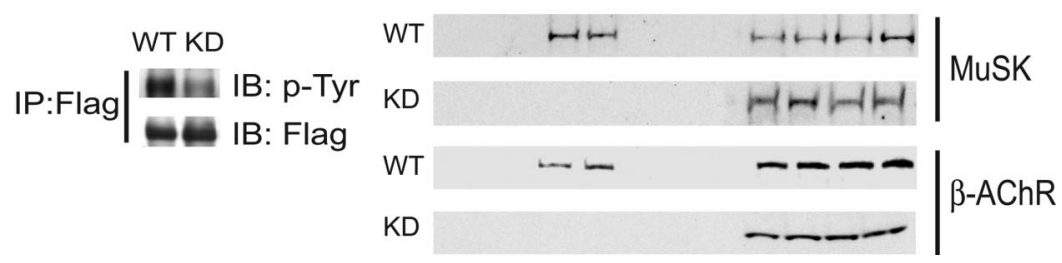


ated $\alpha$-BTX to label the AChR. $\alpha$-BTX-bound AChR was purified by streptavidin beads. As shown in Figures $2 G$ and $3 G$, the amounts of AChRs able to bind to $\alpha$-BTX were similar in control and in MCD- or PDMP-treated myotubes, suggesting that the $\alpha$-BTX-binding activity was not affected when lipid rafts were disrupted.

We also investigated the effect of lipid rafts on the stability of AChR clusters. C2C12 cultures were treated overnight with agrin to induce AChR clusters and switched to media with or without MCD. MCD treatment increased the rate of disappearance of AChR aggregates (Fig. 4A-F). The effect of MCD was detectable within $3 \mathrm{~h}$. The half-life of AChR clusters $(>4 \mu \mathrm{m})$ in control cells was $\sim 7 \mathrm{~h}$, consistent with previous reports (Wallace, 1988; Kim and Nelson, 2000), whereas in the presence of MCD, AChR cluster became less stable, with a half-life $\sim 3 \mathrm{~h}$ (Fig. $4 G$ ). AChR clusters are stable in the presence of agrin, barely decreasing in half-life. Interestingly, the ability of agrin to maintain AChR clusters was impaired in the presence of MCD. The half-life of AChR clusters in the presence of both agrin and MCD was $\sim 3 \mathrm{~h}$, not different from that in the presence of MCD alone (Fig. 4G). These results, together with those that disruption of lipid rafts inhibited agrin/MuSK signaling (below), could suggest that lipid rafts are important for agrin/MuSK signaling, in addition to serving as microdomains that hold AChR together. Together, these results suggest that lipid rafts are required for both the formation and maintenance of AChR clusters.

To determine whether lipid rafts are necessary for AChR clustering in vivo, pregnant mice were injected with MCD to disrupt lipid raft structure, and the effect on AChR clusters was examined. This approach has been used successfully to show the involvement of Cdk5 in AChR clustering in vivo (Lin et al., 2005). MCD was injected into pregnant mice at E14.5, when the NMJ starts to form, or at E18.5, when the formation is complete, once a day for $2 \mathrm{~d}$, and diaphragms were examined at E16.5 and postnatal day 0 (P0), respectively. As shown in Figure 5, MCD decreased the number and size of AChR clusters at both ages, suggesting that lipid rafts may be necessary for AChR cluster formation and maintenance. We are unable to exclude the possibility that the in vivo effect on AChR clustering may result from lipid raft disruption at presynaptic terminals. However, the nerve terminals visualized by anti-synaptophysin antibody was similar in control and MCD-treated muscles. Because of a decrease in AChR clusters, many nerve terminals were not colocalized with

\section{$\leftarrow$}

Figure 6. Agrin-induced MuSK translocation into lipid rafts requires MuSK activation. $\boldsymbol{A}$, MuSK translocation to rafts by neural agrin. Myotubes were treated without (control) or with $5 \mathrm{~nm}$ neural agrin or muscle agrin for $15 \mathrm{~min}$ and fractionated as in Figure $1 A$ and probed with anti-MuSK antibody. Histograms on the right show quantitative analysis of data (means \pm SEM; $n=5$ ). ${ }^{*} p<0.01$, Student's $t$ test. $B$, Time course of neural agrin-induced recruitment of MuSK and AChR into lipid rafts. C2C12 myotubes were treated with $5 \mathrm{~nm}$ neural agrin for indicated times. After discontinuous gradient centrifugation, combined lipid raft fractions (fractions 4 and 5) were subjected to Western blotting with indicated antibodies. Results of quantitative analyses are shown on the right (means $\pm \mathrm{SEM} ; n=5$ ). $C$, Agrin-induced MuSK translocation to rafts prepared by detergent-free methods. Myotubes were treated as in Figure 6 A. Instead of Triton X-100, homogenates were sonicated in sodium carbonate buffer. Thirteen fractions were collected and probed with anti-MuSK and AChR antibodies. D, Time course of agrin-induced recruitment of MuSK and AChR into lipid rafts prepared by detergent-free methods. C2C12 myotubes were treated with 5 nм neural agrin for indicated times. After discontinuous gradient centrifugation, combined lipid raft fractions (fractions 5 and 6) were subjected to Western blotting with indicated antibodies. $\boldsymbol{E}$, Inhibition of MuSK and the AChR recruitment into rafts by the tyrosine kinase inhibitor genistein. $\mathrm{C} 2 \mathrm{C} 12$ myotubes were pretreated with genistein $(100 \mu \mathrm{g} / \mathrm{ml} ; 1 \mathrm{~h}$ ) before stimulation without or with neural agrin ( $5 \mathrm{nm;} 15 \mathrm{~min}$ for MuSK and $60 \mathrm{~min}$ for AChR). Lipid raft fractions were subjected to Western blotting using indicated antibodies. Histograms on the right show quantitative analysis of data (means $\pm \mathrm{SEM} ; n=5$ ). ${ }^{*} p<0.01$, Student's $t$ test. $\boldsymbol{F}$, Agrin induced AChR translocation in MuSK - I - cells transfected with wild-type (WT) MuSK. MuSK - / - cells were transfected with Flag-tagged MuSK wild-type and kinase-dead (KD) constructs, respectively. Transfected cells were stimulated with 5 nm neural agrin (15 min) for MuSK phosphorylation (left panels) and its translocation to lipid rafts (right panels) or with $5 \mathrm{~nm}$ neural agrin ( $8 \mathrm{~h})$ for AChR localization (right panels).
$\alpha$-BTX staining (Fig. 5D, inset), in contrast to the control P0 observations that lipid raft disruption inhibits AChR clustering in cultured muscle cells, suggest a role of lipid rafts in postsynaptic

\section{Agrin-induced translocation of MuSK into lipid rafts}

The observation that $\mathrm{C} 2 \mathrm{C} 12$ myotubes do not form AChR clus. etal proteins necesary for clustering. Alternatively, the are essary for agrin/MuSK signaling machineries. Signaling pathways (Song also prepared lipid rafts using sodium carbonate buffer was present in lipid rafts (Fig. $6 \mathrm{~A}$, fractions 4 and 5 ; $C$, fractions 5 and 6). Interestingly, the application of neural agrin induced an increase of MuSK in lipid rafts. In contrast, muscle agrin, which is mable to stimulate MuSK, was ineffective, suggesting the recruitstudy demonstrated that the partition of $\mathrm{MuSK}$ into rafts peaked between 15 and $30 \mathrm{~min}$ after stimulation (Fig. 6B,D). MuSK basphorylation of , which increases gradually after stimulation (Fig. 6B,D). whether recruitment of MuSK and the AChR into lipid rafts was dependent on MuSK activity. Myotubes were pretreated, before agrin stimulation, with genistein, a tyrosine kinase inhibitor wh to inhibit agrin-induced activation of MuSK and down(Wallace, 1995; Ji et al., 1998). The amount of MuSK and AChRs in the lipid rafts (fractions 4 and 5) was examined at 15 and $60 \mathrm{~min}$, respectively, after agrin stimulation. Treatment with genistein inhibited agrininduced translocation of both MuSK and AChRs into lipid rafts (Fig. 6E), suggesting that MuSK recruitment possibly requires the kinase activity. To further test this hypothesis, MuSK-/- myoblasts were transfected with wild-type or kinaseinactive MuSK together with a vector containing the neomycin resistant gene. Transfection of wild-type MuSK, but not the kinase-dead mutant, restores the ability of MuSK $-/-$ myotubes to respond to agrin (Luo et al., 2002). After selection by growing in G418 medium, transfected myoblasts were induced to form myotubes. Stimulation of agrin caused AChR relocation into lipid raft fractions in MuSK-/- transfected with wild-type MuSK. In cells transfected with kinasedead MuSK, where MuSK phosphoryla- 
tion was impaired (Fig. 6F, left panels), the inactive MuSK remained in nonraft fractions after agrin stimulation (Fig. $6 F$, right panels). These results suggest that MuSK kinase activity is required for $\mathrm{AChR}$ as well as MuSK translocation to lipid rafts.

\section{Inhibition of Agrin/MuSK signaling by MCD and PDMP}

To determine whether agrin/MuSK signaling requires lipid rafts, we examined MuSK tyrosine phosphorylation in agrintreated $\mathrm{C} 2 \mathrm{C} 12$ myotubes in the presence or absence of MCD or PDMP. Neural agrin (5 nM) increased tyrosine phosphorylation of MuSK within $15 \mathrm{~min}$ in control, but not in MCD or PDMP pretreated myotubes (Fig. 7A), suggesting the necessity of lipid rafts in agrin activation of the kinase. Agrin activates GTPases of the Rho family, including Rac1 and Cdc42, which are required for $\mathrm{AChR}$ clustering (Weston et al., 2000; Luo et al., 2002). Such activation is absent in MuSK-/- muscle cells, which could be restored by transfection with wild-type MuSK, suggesting that it is dependent on MuSK (Luo et al., 2002). To determine whether lipid rafts are important for activation of Rho GTPases by agrin, C2C12 myotubes were pretreated with MCD or PMDP before agrin stimulation. The amount of active Rac1, purified by GST-PBD immobilized on beads, was revealed by Western blotting. In control cells, agrin treatment elicited an approximately threefold increase in active Racl (Fig. 7B). However, agrin-induced Rac1 activation was inhibited in myotubes treated with either MCD or PDMP. The AChR becomes tyrosine phosphorylated after agrin stimulation (Wallace, 1991). Phosphorylation of the AChR is implicated in AChR clustering by regulating the association of the receptor with cytoskeletal proteins (Wallace, 1995; Borges and Ferns, 2001). To investigate whether lipid rafts are necessary for agrin-induced AChR phosphorylation, the $\beta$-subunit was immunoprecipitated and examined for phosphotyrosine content by immunoblotting using an anti-phosphotyrosine antibody. Pretreatment with MCD or PDMP attenuated agrin-induced increase in $\beta$-subunit phosphorylation (Fig. 7C). These results suggest that lipid rafts are necessary for activation of MuSK and subsequently of GTPases of the Rho family and tyrosine phosphorylation of the AChR.

\section{Regulation of the interaction between the AChR and rapsyn by lipid rafts}

Rapsyn is believed to bridge the receptor to cytoskeletal proteins (Apel et al., 1995). There is a consensus myristoylation site in the $\mathrm{N}$ terminal of the rapsyn protein. Rapsyn is enriched in the lipid raft fraction when expressed in human embryonic kidney 293 cells (Marchand et al., 2002). However, whether the endogenous rapsyn in muscle cells partition in lipid rafts and, if so, whether it is regulated by agrin remained unclear. To address these ques-
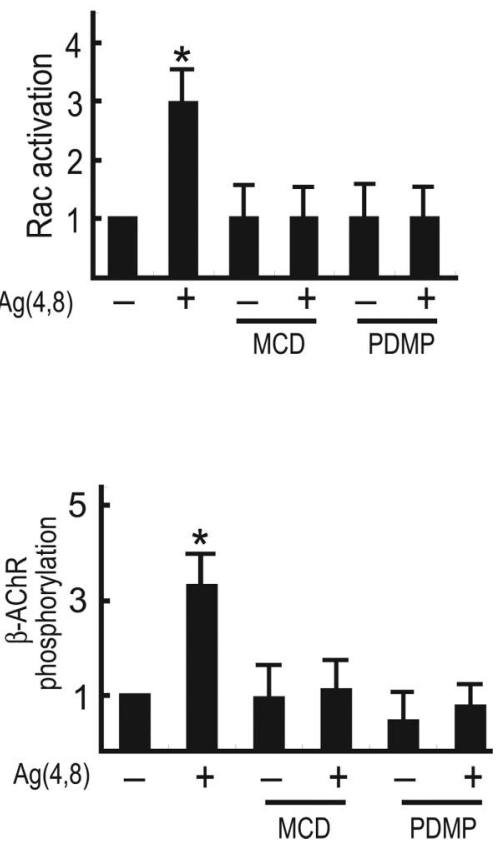

PD: BTX-beads
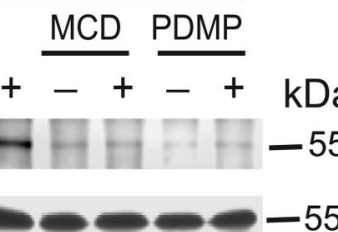
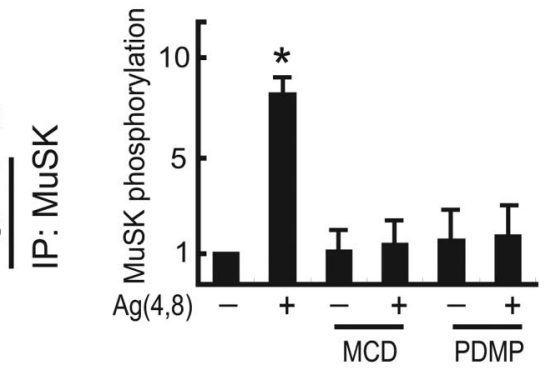

Figure 7. Disruption of lipid rafts attenuates the agrin/MuSK signaling. $A$, Inhibition of agrin-induced MuSK phosphorylation by MCD. Myotubes were pretreated with $2 \mathrm{~mm} \mathrm{MCD} \mathrm{for} 8 \mathrm{~h}$ or $30 \mu \mathrm{M}$ PDMP for $24 \mathrm{~h}$ before stimulation with agrin ( $5 \mathrm{~nm} ; 15 \mathrm{~min}$ ). was immunoprecipitated and examined for tyrosine phosphorylation by immunoblotting (IB) with anti-phosphotyrosine AChR was purified by $\alpha$-BTX immobilized on beads and subjected to Western blotting with anti-phosphotyrosine antibody (top panel) or anti- $\beta$-subunit antibody (bottom panel). Histograms on the right in each panel show quantitative analysis of data (means \pm SEM; $n=5$ ). ${ }^{*} p<0.01$, Student's $t$ test.

tions, control and agrin-treated C2C12 myotubes were subjected to lipid raft isolation. Rapsyn appeared to exist only in fractions comigrating with caveolin-3, with little or minimal amounts in bottom nonraft fractions (Fig. $8 \mathrm{~A}$ ). Importantly, this distribution pattern of rapsyn remained the same after agrin treatment. These results suggest that rapsyn is associated in lipid raft microdomains regardless of agrin stimulation. In contrast, agrin stimulation translocates the AChR from nonraft fractions into lipid rafts (Figs. $1 B, 6 B$ ). Together with a previous observation that the AChR-rapsyn association is increased by agrin (Moransard et al., 2003), these results suggest a role of rapsyn in AChR partition in lipid rafts in response to agrin. This notion predicts that the AChR may not be enriched in the raft fraction in the absence of rapsyn. We tested this hypothesis in muscle cells derived from rapsyn mutant mice (Fuhrer et al., 1999). Rapsyn mutant muscle cells do not form AChR clusters when challenged with agrin (Apel et al., 1997; Fuhrer et al., 1999). In control cells, agrin stimulation increased the amount of the AChR $\beta$-subunit in lipid rafts, in agreement with data from studies of $\mathrm{C} 2 \mathrm{C} 12$ cells 
A

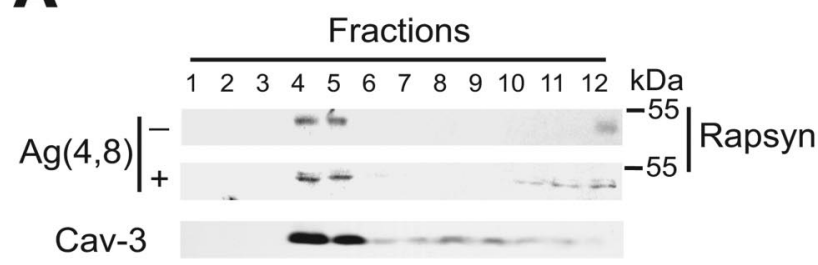

B

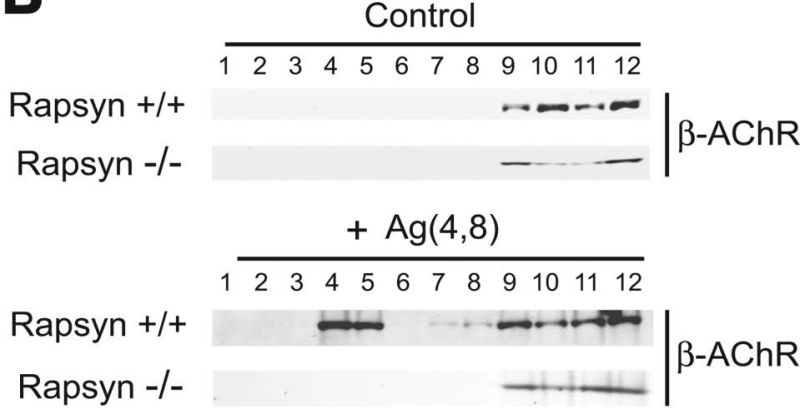

C

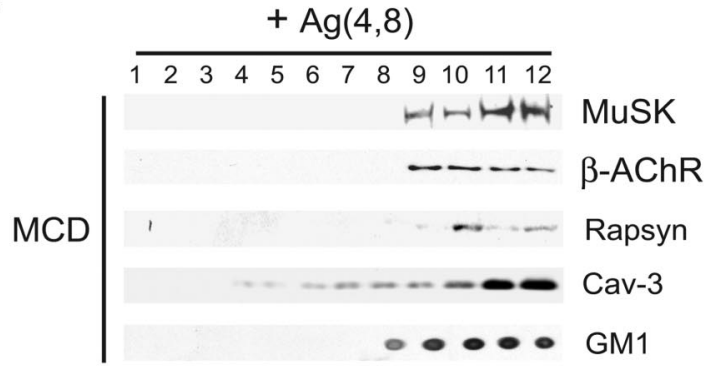

D

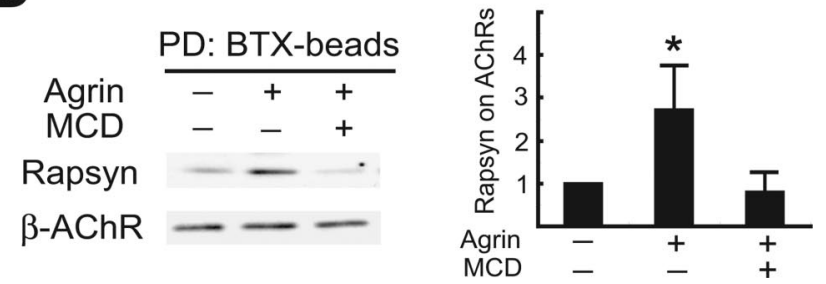

Figure 8. Rapsyn-dependent AChR enrichment in lipid rafts and disruption of lipid rafts inhibit the AChR-rapsyn interaction. $A$, Presence of rapsyn in lipid rafts regardless of agrin stimulation. Control or stimulated myotubes were subjected to fractionation as in Figure $1 \mathrm{~A}$. Twelve fractions were analyzed for rapsyn by Western blotting. $\boldsymbol{B}$, Inability of the AChR to relocate into lipid rafts in rapsyn $-/-$ myotubes stimulated with neural agrin. Rapsyn $-/-$ and control myotubes were stimulated without (top two panels) or with (bottom two panels) neural agrin $(5 \mathrm{~nm} ; 8 \mathrm{~h})$ and subjected to fractionation as in Figure 1 . Fractions were probed with anti- $\beta$-subunit antibody. $C, M C D$ treatment shifts postsynaptic proteins from raft to nonraft fractions. $\mathrm{C} 2 \mathrm{C} 12$ myotubes were pretreated with $2 \mathrm{mM} M C D$ for $8 \mathrm{~h}$ followed by neural agrin stimulation ( $5 \mathrm{~nm}$; $15 \mathrm{~min}$ for MuSK, rapsyn, caveolin-3 and GM1; $16 \mathrm{~h}$ for AChR $\beta$-subunit). Cells were subjected to fractionation as in Figure 1. D, Agrin-induced rapsyn-AChR interaction was inhibited by lipid raft disruption. Myotubes pretreated with MCD ( $2 \mathrm{~mm} ; 8 \mathrm{~h}$ ) were stimulated with neural agrin ( $5 \mathrm{~nm} ; 60 \mathrm{~min})$. The AChR and associated proteins were purified by $\alpha$-BTX immobilized on beads and subjected to Western blotting with anti-rapsyn antibody (top panel) and anti- $\beta$-subunit antibody. Histograms on the right show quantitative analysis of data (means \pm SEM, $n=5$ ). ${ }^{*} p<0.01$, Student's $t$ test.

(Fig. $8 B$ ). However, in muscle cells deficient in rapsyn, the $\beta$-subunit was confined to the bottom nonraft fractions, even after agrin stimulation (Fig. $8 \mathrm{~B}$ ). To further investigate the role of lipid rafts in AChR clusters, we characterized the localization of
AChRs, rapsyn, and MuSK in agrin-stimulated C2C12 myotubes in the presence of MCD, which disrupts lipid rafts. As shown in Figure $8 C$, MCD shifted raft markers, including GM1 and caveolin-3 from the raft fractions to the nonraft fractions. AChRs and MuSK were no longer present in lipid raft fractions in agrintreated myotubes in the presence of MCD. Remarkably, when the AChR was purified after disruption of lipid rafts, it no longer associated with rapsyn, suggesting that the interaction of the two proteins requires lipid rafts (Fig. $8 D$ ). These results suggest that MCD acts by disturbing lipid rafts. The correlation between the shift from raft to nonraft fractions and the inhibitory effect on AChR clustering suggest a role of lipid rafts in AChR clustering. Moreover, lipid rafts may serve as a platform for the AChRrapsyn interaction.

\section{Discussion}

In the present study, we provide evidence that lipid rafts play an important role in regulating AChR clustering. The AChR translocates from nonraft microdomains into the lipid raft fractions after agrin stimulation. This translocation follows MuSK partition into lipid rafts and requires its activation. Immunohistochemical staining shows that the NMJ in vivo is enriched with GM1, a key component of lipid rafts. Disruption of lipid rafts inhibits activation of MuSK and its downstream signaling machineries and subsequent AChR clustering in response to agrin. Rapsyn is located in the lipid raft fraction, regardless of agrin stimulation. Remarkably, perturbation of lipid rafts attenuates the interaction between rapsyn and the AChR. We propose a working model to explain these results. After agrin stimulation, MuSK translocates into lipid rafts to initiate signaling machineries necessary for AChR clustering. Concomitantly, the AChR is recruited to the raft microdomains, where it interacts with rapsyn, which constitutively localized in lipid rafts. Thus, lipid rafts may regulate $\mathrm{AChR}$ clustering by facilitating the agrin/ MuSK signaling and the interaction between the receptor and rapsyn. These results provide insight into mechanisms of AChR cluster formation.

Recent studies suggest that cell membrane is not a homogenous fluid bilayer. It contains discrete lateral microdomains with characteristic subsets of lipids and proteins. One such microdomain is lipid rafts, which have received much attention in the past few years. Lipid rafts are enriched in cholesterol and sphingolipids that exist in the liquid-ordered state. They form islands in the plasma membrane, which is composed mainly of lipids in the liquid-disordered state. Proteins that concentrate in lipid rafts include glycosylphosphatidylinositol-linked proteins (Hooper, 1999; Tansey et al., 2001), doubly acylated proteins such as $\alpha$ subunits of heterotrimeric G-proteins and Src-family kinases (Resh, 1999), and cholesterol-linked or palmitoylated proteins such as Hedgehog (Brown and London, 1998). Concentrating these molecules in a microdomain, lipid rafts may provide a platform for a better interaction between the proteins necessary for coordinated signal transduction. In our study, we found that the partition of MuSK into rafts increases after agrin stimulation, and this translocation depends on its tyrosine kinase activity. The dynamic behavior of MuSK into lipid rafts is most analogous to several tyrosine kinase receptors, including TrkB (Suzuki et al., 2004), c-Ret (Tansey et al., 2001), and ErbB4 (Ma et al., 2003). Once stimulated by the respective ligand, these transmembrane kinases translocate into lipid rafts, and such translocation is necessary for signaling. Remarkably, MuSK translocation to rafts was followed by the recruitment of the AChR, suggesting a sequential signal transduction within lipid rafts. Importantly, lipid raft dis- 
ruption, either by removing cholesterol from the membrane or by reducing the glycosphingolipid level, inhibits MuSK signaling, including MuSK phosphorylation, AChR $\beta$-subunit phosphorylation, and activation of the Rac1 GTPases (Fig. 7). Tyrosine phosphorylated AChR is less detergent extractable than nonphosphorylated AChR, indicating that it is preferentially linked to the cytoskeleton (Ferns et al., 1996; Borges and Ferns, 2001). Phosphorylation could regulate anchoring of the AChR through a direct interaction with a cytoskeletal protein or indirectly via a linker protein. Rapsyn links AChR to cytoskeleton, and agrininduced rapsyn-AChR interaction requires tyrosine kinase activity (Moransard et al., 2003). The Rho family of small GTPases, including Rac and Cdc42, is implicated in coupling agrin signaling to AChR clustering. We showed that disruption of lipid rafts attenuated Rac activation, providing a mechanism for agrin/ MuSK signaling.

Neural agrin induces the interaction of the AChR with rapsyn, which is believed to link the receptor to cytoskeleton (Moransard et al., 2003). The rapsyn-AChR interaction is necessary for AChR clustering. Rapsyn is constitutively localized in lipid rafts (Fig. $8 A$ ), presumably via myristoylation at the $\mathrm{N}$ terminus (Marchand et al., 2002), whereas the AChR is present in nonraft microdomains in naive muscle cells (Fig. $1 A$ ). How could these two proteins interact, being in different subcellular compartments? We show that AChR translocation into lipid rafts occurs gradually, with a maximum after $4 \mathrm{~h}$ of agrin stimulation (Fig. $6 B, D$ ). The AChR kinetics appeared to parallel that of cluster formation, which is detectable at $4 \mathrm{~h}$ and is maximal after $8 \mathrm{~h}$ of agrin stimulation. The mechanism underlying the AChR partition into lipid rafts is unclear. Its increase by agrin suggests that the AChR may undergo chemical modification such as phosphorylation that increases the interaction of the receptor with lipid rafts and/or rapsyn. Once the AChR is recruited into the lipid rafts, it interacts with rapsyn and becomes anchored. This notion is supported by the following observations. First, the AChR partition in lipid rafts requires the presence of rapsyn. In muscle cells deficient in rapsyn, the AChR was not present in lipid rafts even after agrin stimulation (Fig. $8 \mathrm{~B}$ ). Second, when lipid rafts were disrupted by MCD, which prevents the AChR from being recruited, the phosphorylation of the AChR $\beta$-subunit was attenuated (Fig. $7 C)$. Third, lipid raft disruption also inhibits the interaction between the rapsyn and the AChR (Fig. 8D). Note that the amount of rapsyn and surface AChR remains unchanged during the periods of MCD treatment but then are present mainly in nonraft fractions. Under these conditions, however, the interaction between the two proteins was barely detectable regardless of whether the cells were stimulated with agrin (Fig. $8 D$ ). These results suggest that the rapsyn-AChR interaction requires lipid rafts.

In summary, our results indicate that lipid rafts are required for agrin/MuSK signaling pathway and for the interaction of rapsyn with AChRs. Depletion of cholesterol/sphingolipid leads to instability of surface AMPA receptors and gradual loss of synapses (both inhibitory and excitatory) and dendritic spines (Hering et al., 2003). Several ligand-gated ion channels, including the neuronal AChR, the GABA receptor, and the AMPA-type glutamate receptor, have been shown to be in lipid rafts (Becher et al., 2001; Bruses et al., 2001; Dalskov et al., 2005). Therefore, our study may provide insight into the mechanism of CNS synaptogenesis.

\section{References}

Apel ED, Roberds SL, Campbell KP, Merlie JP (1995) Rapsyn may function as a link between the acetylcholine receptor and the agrin-binding dystrophin-associated glycoprotein complex. Neuron 15:115-126.

Apel ED, Glass DJ, Moscoso LM, Yancopoulos GD, Sanes JR (1997) Rapsyn is required for MuSK signaling and recruits synaptic components to a MuSK-containing scaffold. Neuron 18:623-635.

Baird B, Sheets ED, Holowka D (1999) How does the plasma membrane participate in cellular signaling by receptors for immunoglobulin E? Biophys Chem 82:109-119.

Barrantes FJ (2004) Structural basis for lipid modulation of nicotinic acetylcholine receptor function. Brain Res Brain Res Rev 47:71-95.

Becher A, White JH, McIlhinney RA (2001) The gamma-aminobutyric acid receptor $\mathrm{B}$, but not the metabotropic glutamate receptor type-1, associates with lipid rafts in the rat cerebellum. J Neurochem 79:787-795.

Bloch RJ, Froehner SC (1987) The relationship of the postsynaptic 43K protein to acetylcholine receptors in receptor clusters isolated from cultured rat myotubes. J Cell Biol 104:645-654.

Borges LS, Ferns M (2001) Agrin-induced phosphorylation of the acetylcholine receptor regulates cytoskeletal anchoring and clustering. J Cell Biol 153:1-12.

Brown DA, London E (1998) Functions of lipid rafts in biological membranes. Annu Rev Cell Dev Biol 14:111-136.

Bruses JL, Chauvet N, Rutishauser U (2001) Membrane lipid rafts are necessary for the maintenance of the $(\alpha) 7$ nicotinic acetylcholine receptor in somatic spines of ciliary neurons. J Neurosci 21:504-512.

Citores L, Wesche J, Kolpakova E, Olsnes S (1999) Uptake and intracellular transport of acidic fibroblast growth factor: evidence for free and cytoskeleton-anchored fibroblast growth factor receptors. Mol Biol Cell 10:3835-3848.

Dalskov SM, Immerdal L, Niels-Christiansen LL, Hansen GH, Schousboe A, Danielsen EM (2005) Lipid raft localization of GABA A receptor and $\mathrm{Na}^{+}, \mathrm{K}^{+}$-ATPase in discrete microdomain clusters in rat cerebellar granule cells. Neurochem Int 46:489-499.

Evans WE, Coyer RL, Sandusky MF, Van Fleet MJ, Moore JG, Nyquist SE (2003) Characterization of membrane rafts isolated from rat sertoli cell cultures: caveolin and flotillin-1 content. J Androl 24:812-821.

Ferns MJ, Campanelli JT, Hoch W, Scheller RH, Hall Z (1993) The ability of agrin to cluster AChRs depends on alternative splicing and on cell surface proteoglycans. Neuron 11:491-502.

Ferns M, Deiner M, Hall Z (1996) Agrin-induced acetylcholine receptor clustering in mammalian muscle requires tyrosine phosphorylation. J Cell Biol 132:937-944.

Finn AJ, Feng G, Pendergast AM (2003) Postsynaptic requirement for Abl kinases in assembly of the neuromuscular junction. Nat Neurosci 6:717-723.

Frail DE, McLaughlin LL, Mudd J, Merlie JP (1988) Identification of the mouse muscle 43,000-dalton acetylcholine receptor-associated protein (RAPsyn) by cDNA cloning. J Biol Chem 263:15602-15607.

Fuhrer C, Gautam M, Sugiyama JE, Hall ZW (1999) Roles of rapsyn and agrin in interaction of postsynaptic proteins with acetylcholine receptors. J Neurosci 19:6405-6416.

Gautam M, Noakes PG, Mudd J, Nichol M, Chu GC, Sanes JR, Merlie JP (1995) Failure of postsynaptic specialization to develop at neuromuscular junctions of rapsyn-deficient mice. Nature 377:232-236.

Glass DJ, Bowen DC, Stitt TN, Radziejewski C, Bruno J, Ryan TE, Gies DR, Shah S, Mattsson K, Burden SJ, DiStefano PS, Valenzuela DM, DeChiara TM, Yancopoulos GD (1996) Agrin acts via a MuSK receptor complex. Cell 85:513-523.

Harder T, Scheiffele P, Verkade P, Simons K (1998) Lipid domain structure of the plasma membrane revealed by patching of membrane components. J Cell Biol 141:929-942.

Hering H, Lin CC, Sheng M (2003) Lipid rafts in the maintenance of synapses, dendritic spines, and surface AMPA receptor stability. J Neurosci 23:3262-3271.

Hooper NM (1999) Detergent-insoluble glycosphingolipid/cholesterolrich membrane domains, lipid rafts and caveolae. Mol Mem Biol 16:145-156.

Inokuchi J, Mason I, Radin NS (1987) Antitumor activity via inhibition of glycosphingolipid biosynthesis. Cancer Lett 38:23-30.

Janes PW, Ley SC, Magee AI, Kabouridis PS (2001) The role of lipid rafts in $\mathrm{T}$ cell antigen receptor (TCR) signalling. Semin Immunol 12:23-34. 
Ji RR, Bose CM, Lesuisse C, Qiu D, Huang JC, Zhang Q, Rupp F (1998) Specific agrin isoforms induce cAMP response element binding protein phosphorylation in hippocampal neurons. J Neurosci 18:9695-9702.

Kim S, Nelson PG (2000) Involvement of calpains in the destabilization of the acetylcholine receptor clusters in rat myotubes. J Neurobiol 42:22-32.

Lin W, Dominguez B, Yang J, Aryal P, Brandon EP, Gage FH, Lee KF (2005) Neurotransmitter acetylcholine negatively regulates neuromuscular synapse formation by a Cdk5-dependent mechanism. Neuron 46:569-579.

Luo Z, Wang Q, Zhou J, Wang J, Liu M, He X, Wynshaw-Boris A, Xiong W, Lu B, Mei L (2002) Regulation of AChR clustering by dishevelled interacting with MuSK and PAK1. Neuron 35:489-505.

Luo ZG, Je HS, Wang Q, Yang F, Dobbins GC, Yang ZH, Xiong WC, Lu B, Mei L (2003) Implication of geranylgeranyltransferase I in synapse formation. Neuron 40:703-717.

Ma L, Huang YZ, Pitcher GM, Valtschanoff JG, Ma YH, Feng LY, Lu B, Xiong WC, Salter MW, Weinberg RJ, Mei L (2003) Ligand-dependent recruitment of the ErbB4 signaling complex into neuronal lipid rafts. J Neurosci 23:3164-3175.

Marchand S, Devillers-Thiery A, Pons S, Changeux JP, Cartaud J (2002) Rapsyn escorts the nicotinic acetylcholine receptor along the exocytic pathway via association with lipid rafts. J Neurosci 22:8891-8901.

McMahan UJ (1990) The agrin hypothesis. Cold Spring Harb Symp Quant Biol 55:407-418.

Mineo C, Gill GN, Anderson RG (1999) Regulated migration of epidermal growth factor receptor from caveolae. J Biol Chem 274:30636-30643.

Moransard M, Borges LS, Willmann R, Marangi PA, Brenner HR, Ferns MJ, Fuhrer C (2003) Agrin regulates rapsyn interaction with surface acetylcholine receptors, and this underlies cytoskeletal anchoring and clustering. J Biol Chem 278:7350-7359.

Nagafuku M, Kabayama K, Oka D, Kato A, Tani-ichi S, Shimada Y, OhnoIwashita Y, Yamasaki S, Saito T, Iwabuchi K, Hamaoka T, Inokuchi J, Kosugi A (2003) Reduction of glycosphingolipid levels in lipid rafts affects the expression state and function of glycosylphosphatidylinositolanchored proteins but does not impair signal transduction via the $\mathrm{T}$ cell receptor. J Biol Chem 278:51920-51927.

Resh MD (1999) Fatty acylation of proteins: new insights into membrane targeting of myristoylated and palmitoylated proteins. Biochim Biophys Acta 1451:1-16.
Sanes JR, Lichtman JW (2001) Induction, assembly, maturation and maintenance of a postsynaptic apparatus. Nat Rev Neurosci 2:791-805.

Schon A, Freire E (1989) Thermodynamics of intersubunit interactions in cholera toxin upon binding to the oligosaccharide portion of its cell surface receptor, ganglioside GM1. Biochemistry 28:5019-5024.

Simons K, Ikonen E (1997) Functional rafts in cell membranes. Nature 387:569-572.

Simons K, Toomre D (2001) Lipid rafts and signal transduction. Nat Rev Mol Cell Biol 1:31-39.

Song KS, Li S, Okamoto T, Quilliam LA, Sargiacomo M, Lisanti MP (1996) Co-purification and direct interaction of Ras with caveolin, an integral membrane protein of caveolae microdomains. Detergent-free purification of caveolae microdomains. J Biol Chem 271:9690-9697.

Suzuki S, Numakawa T, Shimazu K, Koshimizu H, Hara T, Hatanaka H, Me L, Lu B, Kojima M (2004) BDNF-induced recruitment of TrkB receptor into neuronal lipid rafts: roles in synaptic modulation. J Cell Biol 167:1205-1215

Tanowitz M, Si J, Yu D-H, Feng G-S, Mei L (1999) Regulation of neuregulin-mediated AChR synthesis by protein tyrosine phosphatase SHP2. J Neurosci 19:9426-9435.

Tanowitz MB, Mei L (1996) Surgical denervation increases protein tyrosine phosphatase activity in skeletal muscle. Brain Res 712:299-306.

Tansey MG, Baloh RH, Milbrandt J, Johnson Jr EM (2001) GFRalphamediated localization of RET to lipid rafts is required for effective downstream signaling, differentiation, and neuronal survival. Neuron 25:611-623.

Trinidad JC, Cohen JB (2004) Neuregulin inhibits acetylcholine receptor aggregation in myotubes. J Biol Chem 279:31622-31628.

Wallace BG (1988) Regulation of agrin-induced acetylcholine receptor aggregation by $\mathrm{Ca}^{++}$and phorbol ester. J Cell Biol 107:267-278.

Wallace BG (1991) The mechanism of agrin-induced acetylcholine receptor aggregation. Philos Trans R Soc Lond B Biol Sci 331:273-280.

Wallace BG (1995) Regulation of the interaction of nicotinic acetylcholine receptors with the cytoskeleton by agrin-activated protein tyrosine kinase. J Cell Biol 128:1121-1129.

Weston C, Yee B, Hod E, Prives J (2000) Agrin-induced acetylcholine receptor clustering is mediated by the small guanosine triphosphatases Rac and Cdc42. J Cell Biol 150:205-212. 